\title{
PERICARDITIS ASSOCIATED WITH RHEUMATOID ARTHRITIS
}

\author{
BY \\ B. A. LATHAM* \\ Royal North Shore Hospital of Sydney, Australia
}

Evidence of old or recent pericarditis is a frequent autopsy finding in rheumatoid arthritis. The histological appearances are generally non-specific, but the incidence is so high that an aetiological relationship must be assumed. Sokoloff (1953) reviewed the autopsy findings in 101 cases of rheumatoid arthritis (including seventeen which probably had ankylosing spondylitis by present criteria), and found that 40.6 per cent. showed evidence of pericarditis, compared with $8 \cdot 8$ per cent. of 1,154 consecutive unselected autopsies. Egelius, Göhle, Jonsson, and Wahlgren (1955) found evidence of pericarditis in seven out of thirteen autopsies in rheumatoid arthritis; they also reviewed the literature and found that 93 out of 288 reported autopsies of cases of rheumatoid arthritis showed evidence of pericarditis, an incidence of $32 \cdot 3$ per cent.

Clinical reports of pericarditis associated with rheumatoid arthritis are still remarkably few. The purpose of this paper is to present three further cases, each associated with effusion, all of which came to autopsy.

\section{Case Reports}

Case 1, a 60-year-old man, was admitted to hospital on August 19, 1964, with one week's history of acute pericarditis for which tetracycline had been prescribed. Rheumatoid arthritis had been present for 13 years.

Examination.-He was slightly dyspnoeic with a pyrexia of $101^{\circ} \mathrm{F}$., pulse 100 per min., blood-pressure $110 / 80$, jugular venous pressure raised $1 \frac{1}{2}$ in., heartsounds diminished. Advanced rheumatoid changes were present with subcutaneous nodules over both forearms, "swan's neck" deformity of the fingers, and swelling

*Frank G. Spurway Fellow of Australian Rheumatism Council. and deformity of the elbows, wrists, and knees. None of the joints was actively inflamed.

Laboratory Investigations.-Haemoglobin $11 \cdot 3 \mathrm{~g}$. per cent.; white blood count 37,000 per c. mm. with 88 per cent. neutrophils; erythrocyte sedimentation-rate $3 \mathrm{~mm}$. per $\mathrm{hr}$ (Westergren); chest $x$ ray-slight enlargement of cardiac shadow.

Progress.-It was agreed that the pericarditis was probably infective and tetracycline was continued. One week later cardiac tamponade developed necessitating pericardial aspiration which yielded $85 \mathrm{ml}$. turbid, yellow fluid and gave immediate relief. The fluid contained numerous pus cells; protein $4.0 \mathrm{~g}$. per cent.; sugar $15 \mathrm{mg}$. per cent.; culture sterile.

The clinical impression was still that he had an infective pericarditis which had been partially suppressed by chemotherapy, ampicillin ("Penbritin") was therefore given in place of tetracycline. Three further aspirations were required over the next week. He then improved temporarily but after another week the pericardial effusion re-accumulated with alarming rapidity (Figs 1 and 2, overleaf) and tamponade developed again. Aspiration yielded $300 \mathrm{ml}$. turbid, brown fluid with similar laboratory findings.

At this stage it was strongly suspected that the pericarditis might be rheumatoid in origin and he was given prednisone $60 \mathrm{mg}$. per day together with erythromycin and chloramphenicol as the possibility of infection still could not be discounted entirely. This was followed by dramatic improvement and over the next 2 weeks the prednisone was reduced steadily to $7.5 \mathrm{mg}$. per day. The patient then relapsed and developed a left pleural effusion in addition to recurrence of pericardial effusion. Pleural aspiration yielded $40 \mathrm{ml}$. yellow, opalescent fluid showing 5 to 10 pus cells per high-power field; protein $2 \cdot 8 \mathrm{~g}$. per cent.; sugar $10 \mathrm{mg}$. per cent.; culture sterile.

A firm diagnosis was then made of rheumatoid pericarditis. Prednisone was restored to $60 \mathrm{mg}$. per day and antibiotics were withdrawn. A generalized, red macular rash appeared for a few days at this time. The 


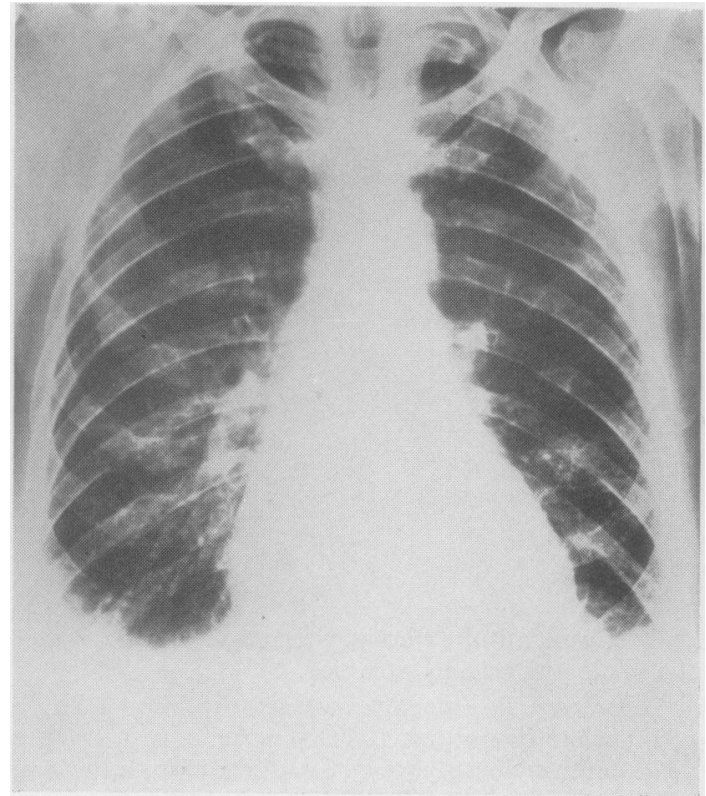

Fig. 1.-Case 1, Chest $x$ ray on September 10, 1964.

pleural and pericardial effusions were resorbed and did not recur with slow reduction of the prednisone to $15 \mathrm{mg}$. per day. However, he remained somewhat dyspnoeic with a tachycardia of 100 to 120 per min. and ankle oedema developed. Digitilization brought the pulse down to 80 to 100 per min. and abolished the oedema, but he was still dyspnoeic on exertion when discharged on October 30, 1964, receiving prednisone $15 \mathrm{mg}$. per day and digoxin $0.25 \mathrm{mg}$. three times a day. The joints remained quiescent apart from some pain and swelling in the left ankle.

Further investigations during his stay in hospital had included the following:

Blood: Haemoglobin $9 \cdot 7$ to 13.4 g. per cent.; white cell count 14,300 to 36,000 per c. mm. with persistent neutrophilia; erythrocyte sedimentation-rate 6 to $22 \mathrm{~mm}$. per hr (Westergren); Waaler-Rose test positive, D.A.T. $1: 128$; L.E.-cells not found on three searches; culture sterile; urea $75 \mathrm{mg}$. per cent. initially, later $40 \mathrm{mg}$. per cent.

Pericardial Fluid: Repeated culture and guinea-pig inoculation sterile; sugar 20 to $35 \mathrm{mg}$. per cent.; latex test for rheumatoid factor positive.

$X$-rays: Advanced erosive changes present in the hands and feet.

After discharge the patient remained relatively well for 6 weeks until December 12, when he awoke short of breath; on admission to hospital 3 hours later, he was in severe respiratory distress with intense cyanosis. Peri-

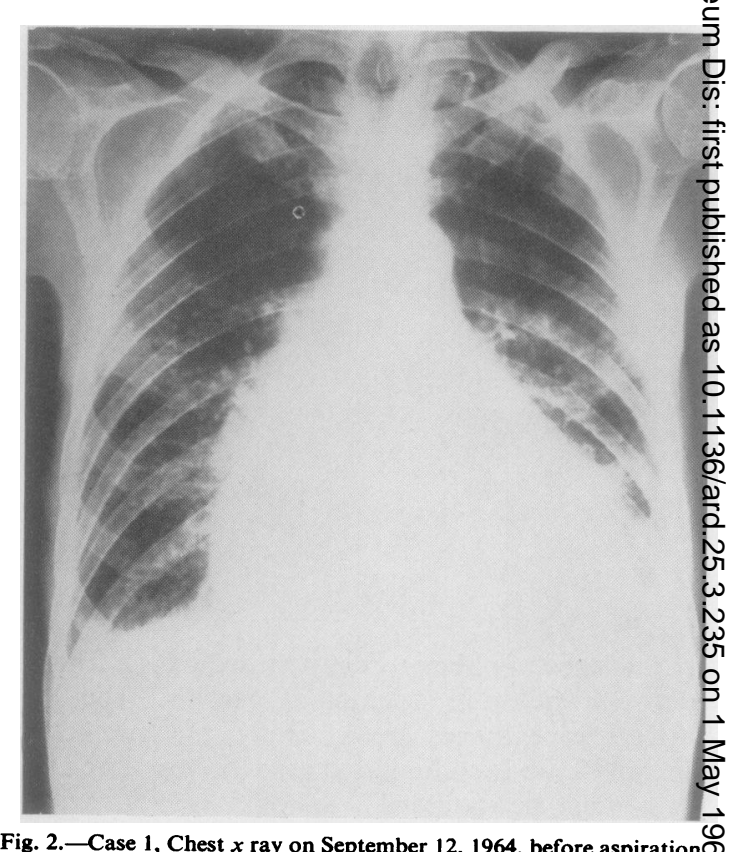

Fig. 2.-Case 1, Chest $x$ ray on September 12, 1964, before aspiration of $300 \mathrm{ml}$. pericardial fluid, showing marked increase in pericardialos effusion in the course of 2 days.

cardial aspiration yielded only a small quantity of fluid without relief. Intravenous hydrocortisone was given in $\frac{\square}{\square}$ addition to the usual supportive therapy, but he died $5 \stackrel{\mathbb{2}}{2}$ hours later.

Autopsy.-There was a fibrinous pericarditis, both layers of pericardium being thickened and covered with fibrin. The pericardial cavity contained $2 \mathrm{oz}$. yellow: fluid. Both ventricles were pale and flabby and the left was slightly hypertrophied. Only moderate coronary? atheroma was present and the atria and heart-valves were normal.

The lungs were oedematous and had dense adhesions $\delta$ over both apices and fine adhesions over the anterior surface on the left.

Histological examination showed fibrous thickening of $\frac{\text { ? }}{2}$ the pericardium which was infiltrated by large numbers of plasma-cells and lymphocytes, with a fibrinous exudate on the surface (Fig. 3, opposite); the synovium of the left ankle $N$ showed similar changes. Other viscera were normal apart from changes of congestion. No cause of death $C$ could be found other than pericarditis which was deve- $N$ loping into the chronic adhesive stage. There was no evidence of any disease process other than rheumatoid 0 arthritis and, in particular, no evidence of systemic $\frac{\sim}{\Phi}$ lupus erythematosus nor of polyarteritis.

Family History.-A sister, who was also observed 0 personally, had died earlier in 1964 with "malignant" rheumatoid arthritis showing features of Sjögren's syn- $\stackrel{\mathbb{D}}{O}$ drome, peripheral neuropathy, and gangrene of the foot. 


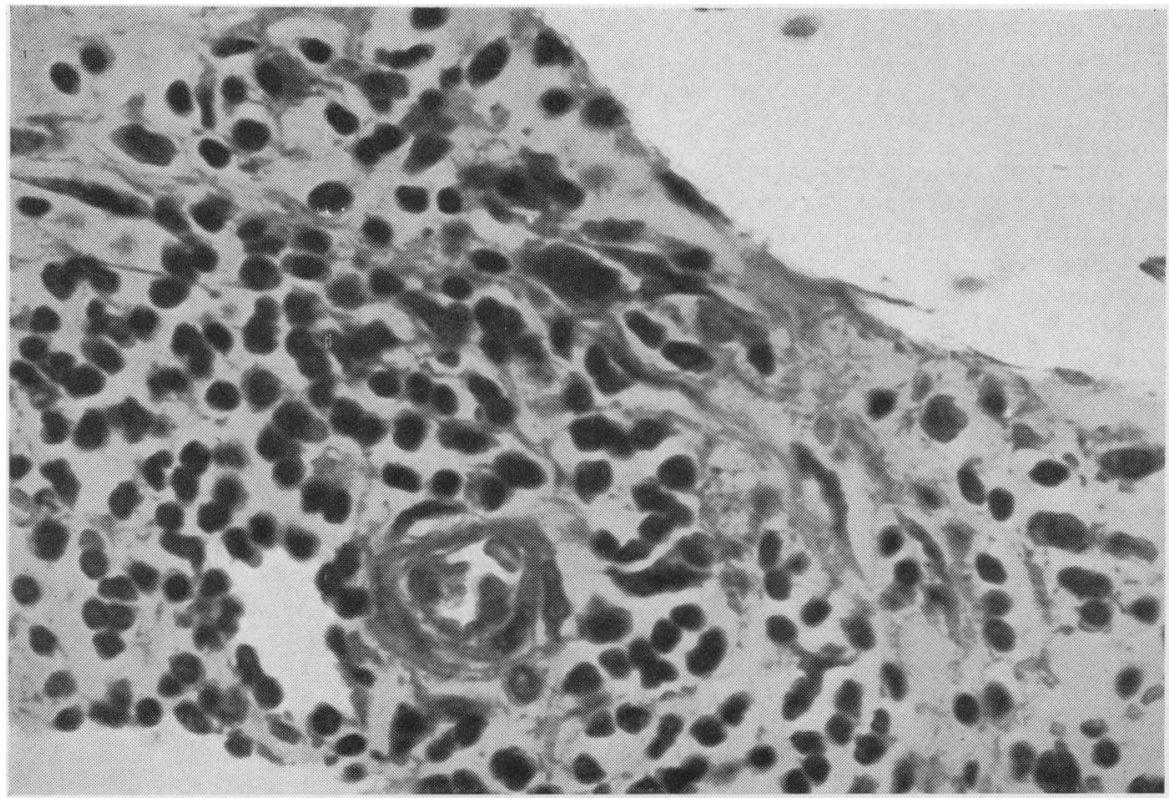

Fig. 3.-Case 1, Pericardium showing marked infiltration by lymphocytes and plasma-cells. Haematoxylin and eosin. $\times 265$.

Observation of Case 1 prompted me to study the records of all patients admitted to the Royal North Shore Hospital in the period 1941-60 in whom the primary diagnosis was pericarditis. There were 28 such patients; two had rheumatoid arthritis and one may have had possible rheumatoid arthritis.

Case 2, a 64-year-old woman, was admitted to hospital on July 17, 1953. Rheumatoid arthritis had been present for 20 years. Dyspnoea on exertion had been present 15 years but had been very much worse for 2 weeks, when it was associated with cyanosis, anorexia, oliguria, and swelling of the face, legs, and abdomen.

Examination.-She showed signs of congestive cardiac failure together with arthritic changes in the hands, knees, and ankles.

She died 3 days later.

Autopsy.-There was organizing fibrinous pericarditis. No aetiological diagnosis was made at the time, but sections of the pericardium were available for re-appraisal and showed changes strongly suggestive of rheumatoid pericarditis. There was fibrous thickening of the pericardium together with focal collections of lymphocytes and many plasma-cells (Fig. 4).

Case 3, a 59-year-old man, was first admitted to hospital on August 25, 1958, complaining of breathlessness for 3 weeks. Rheumatoid arthritis affecting the hands, knees, feet, and ankles had been present for 18 months.

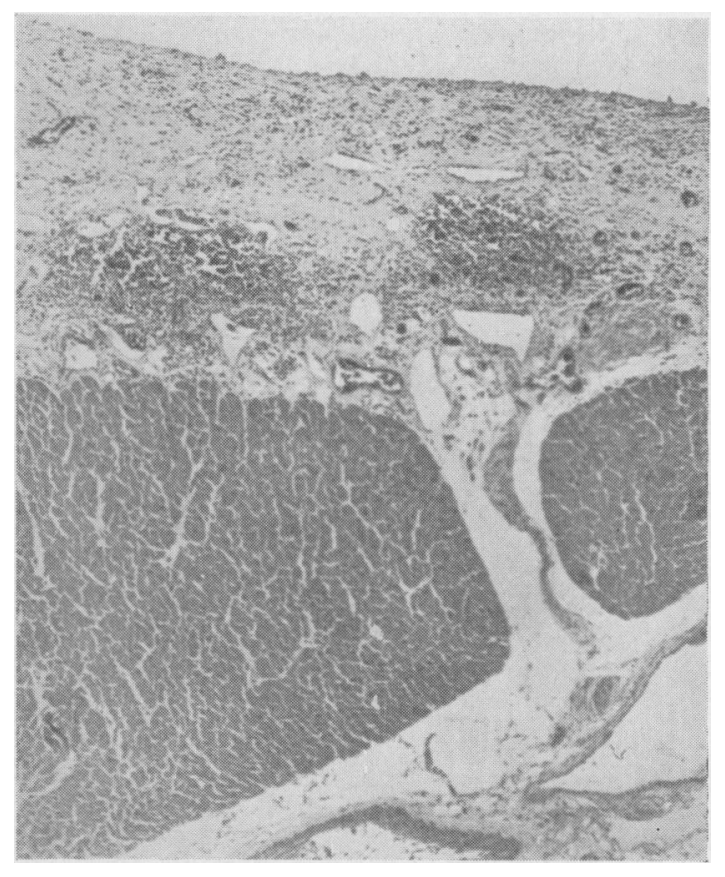

Fig. 4.-Case 2, Pericardium, showing fibrous thickening together with focal collections of lymphocytes. Haematoxylin and eosin. $\times 30$. 
Examination.-There were signs of congestive cardiac failure with a blood-pressure of 95/70. Chest $x$ ray showed gross enlargement of the cardiac shadow and $x$ ray of the hands well-marked erosive changes.

Progress.-Digoxin and chlorothiazide were given without much benefit. Repeat chest $x$ ray on September 1, 1958 (Fig. 5) together with screening of the chest were strongly suggestive of pericardial effusion. Rheumatoid pericarditis was diagnosed and the patient was given prednisone $30 \mathrm{mg}$. per day with rapid improvement. This was withdrawn over the course of 3 weeks and he was discharged well on October 20, and remained well until April, 1960, when partial gastrectomy was performed at another hospital for bleeding duodenal ulcer. From August, 1960, he complained of increasing weakness and lethargy and he was re-admitted to our hospital on January 13, 1961, with signs of congestive cardiac failure and hepatosplenomegaly. He died 6 days later.

Autopsy showed Hodgkin's disease of the spleen, bone marrow, intra-abdominal lymph-nodes, and kidneys. Fibrinous pericarditis was present. Histological examination of the pericardium showed infiltration with malignant cells including Reed-Sternberg multinucleated giant cells (Fig. 6).

Case 4, a 56-year-old man, who was admitted to hospital on September 5, 1947, had been unwell for 6 months and dyspnoeic for 3 months. His history contains the tantalizing information "Right ankle swollen for 3 months. Deformity of right hand 3 months", but no further reference is made to the locomotor system in the examination, and he died the next day.

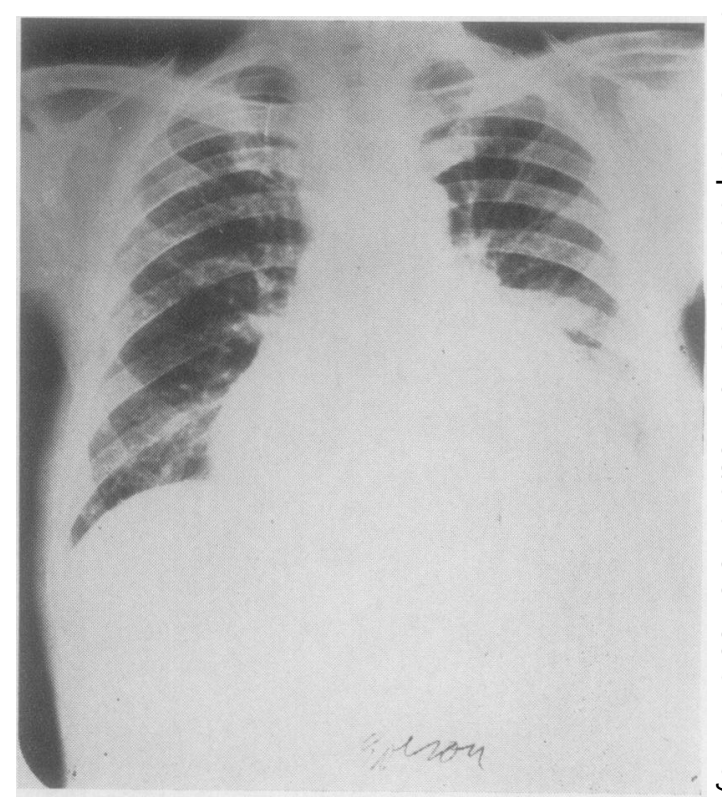

Fig. 5.-Case 3, Chest $x$ ray on September 1, 1958, showing gross $\vec{\varphi}$ enlargement of cardiac shadow; screening suggested that this was in fact due to pericardial effusion.

Autopsy.-There was haemorrhagic pericarditis with a large effusion. No sections of the pericardium were available for re-appraisal, nor was there any mention of the joints in the autopsy report.

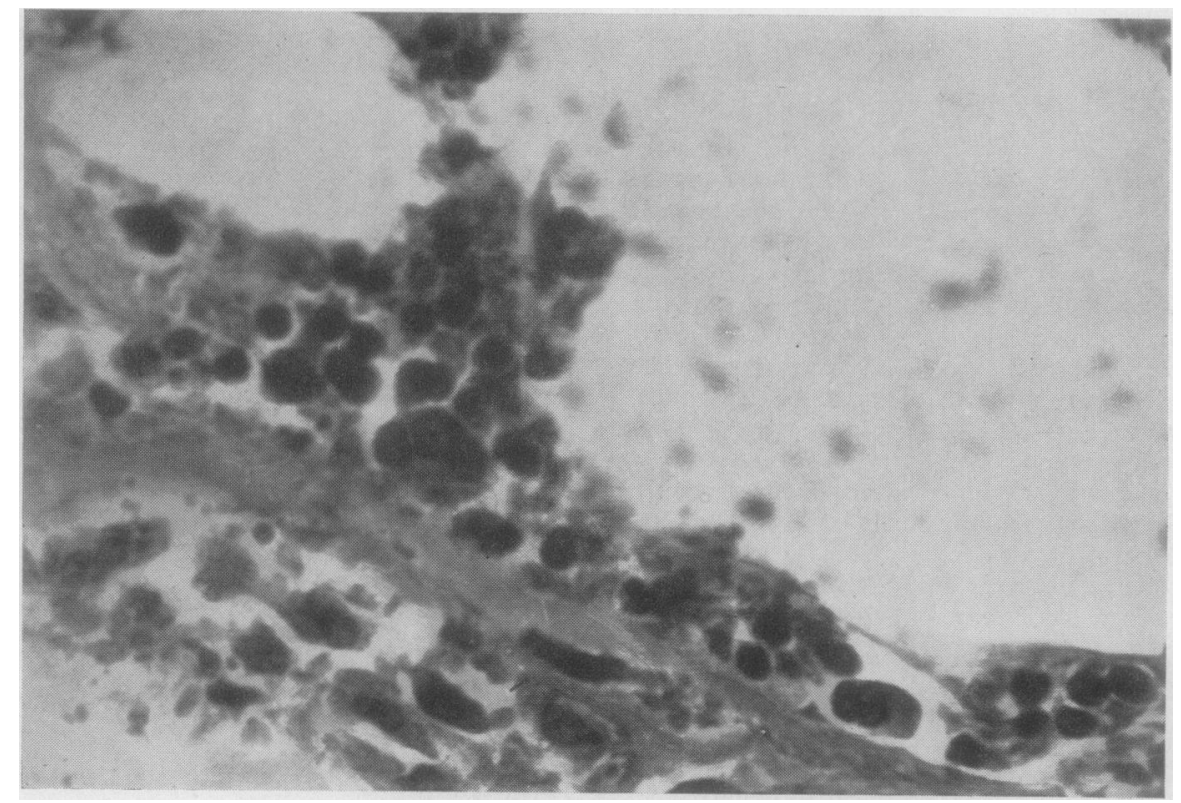

Fig. 6. Case 3, Pericardium, showing presence of multi-nucleated Reed-Sternberg giant-cells. Haematoxylin and eosin. $\times 525$. 


\section{Comment}

There is a marked discrepancy between the abundance of autopsy reports of rheumatoid pericarditis and the dearth of clinical reports. Thomas and Morgan (1956) reported three cases, two showing L.E.-cells, all of which settled with conservative management. Grossman, Kaplan, Ownby, and Grossman (1962) reported three cases in which pericarditis preceded the usual articular manifestations of rheumatoid arthritis by periods of 4 to 11 months; the pericarditis settled with steroid therapy in each case.

Reports of pericardial effusion in rheumatoid arthritis are few and of cardiac tamponade fewer still.

Stern and Sobel (1961) reported the case of a 50-yearold woman with nodular rheumatoid arthritis of 21 years' duration who had had acute pericarditis 11 years earlier. Shortly before admission to hospital she developed pulmonary oedema from mitral stenosis and subsequently stopped steroid therapy, which she had received for 6 years. After admission she developed cardiac tamponade, and also a red macular rash. Autopsy showed haemorrhagic pericarditis with $350 \mathrm{ml}$. reddish-brown fluid in the pericardial sac.

Partridge and Duthie (1963) reported the case of a 49year-old man with nodular, erosive rheumatoid arthritis of 4 years' duration, who developed pericarditis and cardiac tamponade. As this was not relieved by tapping $500 \mathrm{ml}$. sanguinous fluid, pericardiectomy was performed. Histology showed chronic thickening of the pericardium with fibrinous exudation and infiltration by lymphocytes and plasma cells.

Szatkowski and Inoue (1963) reported the case of a 53year-old man, with sero-positive rheumatoid arthritis of 3 years' duration, who developed pericarditis with an effusion containing cholesterol crystals. Pericardiectomy was performed as it was felt that the patient was in the early stages of constriction. Microscopy showed granulomatous pericarditis. The authors considered that this was tuberculous as he reacted strongly to 1:1,000 old tuberculin and responded well to antituberculous chemotherapy, but repeated cultures failed to grow tubercle bacilli. In retrospect it seems quite possible that he may really have had rheumatoid pericarditis, particularly since Newcombe and Cohen (1965) have described a case of sero-positive rheumatoid arthritis with a chylous synovial effusion containing cholesterol crystals, and cited four other cases in the literature in which patients with severe rheumatoid arthritis showed cholesterol crystals in the synovial fluid.

Granirer (1946), under the title "pericardial effusion in rheumatoid arthritis", reported the case of a man from whom 1 litre of pericardial fluid was aspirated, after which he settled down on salicylates. However, study of the history and clinical photograph suggests that this patient had ankylosing spondylitis rather than rheumatoid arthritis.
Gimlette (1959) surveyed 62 cases of constrictive pericarditis and found that five had active rheumatoid arthritis; four had arthritis for some years before the onset of cardiac symptoms, and the fifth developed arthritis 3 months after the acute pericarditis which initiated constriction. Operation was performed on three, but was only curative in one. McMurray, Cayer, and Cornatzer (1951) had earlier reported the case of a 38-year-old man with a history of constrictive pericarditis for 18 months and a rheumatoid type of polyarthritis for 4 years who responded well to pericardiectomy. This histology was reported as compatible with rheumatoid pericarditis, but Stern and Sobel (1961) considered that a tuberculous or mycotic aetiology was more likely in view of associated calcification in the pericardium and adrenals.

Since Gimlette's report, several further pericardiectomies have been reported for constrictive pericarditis in rheumatoid arthritis. Keith (1962) and Kerr-Taylor (1963) reported single cases, both successful. Glyn and Pratt-Johnson (1963) reported another, in a 51-year-old man who presented with a spontaneous right pneumothorax, and then developed a right pleural effusion and pericardial effusion leading to constriction; 2 weeks after operation he developed acute, sero-positive rheumatoid arthritis. Tubbs, Slade, and Turner-Warwick (1964) reported operations on three cases of constrictive pericarditis with rheumatoid arthritis of 2 to 12 years' duration. Two gave a definite history of pericarditis with effusion 10 months and 4 years respectively from the onset of arthritis; the main histological feature of the pericardium in each case was fibrous thickening without calcification. The patients were all well from the cardiac view-point when the report was written, 3 years after surgery in two cases and 14 months in the third. Seventeen other pericardiectomies were performed during the period in which these cases were collected.

\section{Discussion}

Why are clinical reports of pericarditis in rheumatoid arthritis so limited when autopsy studies show that $\mathbf{3 0}$ to $\mathbf{4 0}$ per cent. of rheumatoid arthritics show evidence of pericarditis? One reason, pointed out by Wilkinson (1962), is that the pericarditis is frequently overlooked by both patient and physician as the symptoms are usually mild and tend to be overshadowed by the joint symptoms. Another reason may be that cases are treated by general physicians or cardiologists who are unaware of the association between pericarditis and rheumatoid arthritis, and that these cases are therefore labelled as cases of idiopathic pericarditis with coincidental rheumatoid arthritis. Case 2 is an example of this, and Case 4 may have had possible rheumatoid arthritis which aroused no interest at the time.

There is no relation between the duration of rheumatoid arthritis and onset of pericarditis, which may even precede the articular manifestations of the 
disease. A similar situation exists in pleurisy associated with rheumatoid arthritis; Ward (1961) showed that a pleural effusion may precede the articular manifestations.

Rheumatoid pericarditis is usually a benign condition, but Cases 1 and 2 and a review of the literature show that this is by no means invariable. A small number of patients may die in the acute stage from cardiac tamponade or may progress to constriction. It is noteworthy that, although steroid therapy was life-saving in Case 1 and suppressed further exudation of pericardial fluid, it did not prevent an ultimately fatal outcome. It is felt, in retrospect, that the patient's continuing symptoms were an indication of early constriction and that he should have been offered pericardiectomy. Tubbs and others (1964) pointed out that patients with rheumatoid pericarditis may progress to constriction despite long-term steroid therapy.

Rheumatoid arthritis is an important cause of constrictive pericarditis and the old teaching that the latter is always tuberculous is no longer tenable. Adding the figures of Tubbs and others(1964) to those of Gimlette (1959), rheumatoid arthritis was the probable aetiological factor in eight out of 82 cases, an incidence of 9.4 per cent. It is likely to assume greater proportional significance with the continuing decline in tuberculosis. Pericardiectomy is usually curative.

Case 1 illustrates the difficulty and uncertainty which may attend the diagnosis of pericarditis associated with rheumatoid arthritis. The fever, leucocytosis, and appearance of the pericardial fluid all suggested infective pericarditis initially and rheumatoid pericarditis was not considered until there had been failure to respond to prolonged chemotherapy. The low concentration of sugar in the pericardial fluid, which varied from 15 to $35 \mathrm{mg}$. per cent., has not been described specifically in rheumatoid pericarditis; it is not, however, surprising in view of the very low concentrations reported in rheumatoid pleural effusions by Carr and Mayne (1962).

Case 3 is interesting in that a firm diagnosis of rheumatoid pericarditis was made in 1958, and the excellent response to steroid therapy appeared to support this diagnosis. However autopsy, $2 \frac{1}{2}$ years later, showed Hodgkin's disease with infiltration of the pericardium by malignant cells. It is, of course, impossible to state categorically whether the pericardial effusion in 1958 was due to rheumatoid pericarditis or to Hodgkin's disease, but the clinicians and pathologist concerned with the case favoured the latter. The coincidence of rheumatoid arthritis and $\frac{5}{3}$ Hodgkin's disease may have been more than for- $\underline{-}$ tuitous; Lea (1964) has shown a statistically significant association between the reticuloses and $\vec{\Rightarrow}$ rheumatic disease, the reason for which is unknown.

\section{Conclusions}

The diagnosis of rheumatoid pericarditis must, to $\mathrm{a} \stackrel{\mathrm{D}}{\overrightarrow{\mathrm{D}}}$ certain extent, remain one of exclusion. Rheuma- $\frac{a}{\alpha}$ toid arthritics remain subject to other causes of o pericarditis as in Case 3; however, if a rheumatoid $\vec{\circ}$ arthritic does develop pericarditis, then it is most $\overrightarrow{-}$ likely to be rheumatoid in origin. If an effusion is $\vec{\omega}$ present, sterile fluid with a low sugar concentration is strongly in favour of the diagnosis. In constric- $\rho$ tive pericarditis associated with rheumatoid arthritis, $N$ fibrous thickening of the pericardium without $\omega$ calcification is strongly in favour of a rheumatoid $\underset{W}{N}$ aetiology, whilst the presence of focal collections of $\mathrm{G}$ lymphocytes and plasma-cell infiltration is even more suggestive.

The Waaler-Rose test is a worthwhile investigation in any patient with pericarditis of obscure aetiology; likewise a latex test for rheumatoid factor should be performed on pericardial fluid obtained in such circumstances.

Rheumatoid pericarditis is more common than is generally recognized; it should be considered when- $\overline{0}$ ever a rheumatoid arthritic develops chest-pain, and this symptom should never be dismissed lightly as $\stackrel{\square}{\complement}$ 'rheumatism' of the chest.

\section{Summary}

Three cases are reported of pericarditis with effusion in association with rheumatoid arthritis, and a fourth in association with possible rheumatoid arthritis. The autopsy findings are described in $\frac{5}{3}$ each case. Of the three patients with definite rheumatoid arthritis, two showed histological find-윽 ings consistent with rheumatoid pericarditis, and the third had Hodgkin's disease. Attention is drawn to the low sugar concentration of the pericardial effusion in one case.

I am grateful to Dr. I. R. Vanderfield, General Medical Superintendent, for permission to report these cases, to 0 Dr. W. H. Payne, Assistant Morbid Anatomist, who N kindly reviewed the histological material and to Dr. Jang Barrett for the photomicrographs.

\section{REFERENCES}

Carr, D. T., and Mayne, J. G. (1962). Amer. Rev. resp. Dis., 85, 345.

Egelius, N., Göhle, O., Jonsson, E., and Wahlgren, J. (1955). Ann. rheum. Dis., 14, 11. 
Gimlette, T. M. D. (1959). Brit. Heart J., 21, 9.

Glyn, J. H., and Pratt-Johnson, J. H. (1963). Brit. med. J., $1,262$.

Granirer, L. W. (1946). Med. Clin. N. Amer., 30, 562.

Grossman, L. A., Kaplan, H. J., Ownby, F. D., and Grossman, M. (1962). Arch. intern. Med., 109, 665.

Keith, T. A. (1962). Circulation, 25, 477.

Kerr-Taylor, H. (1963). Rheumatism, 19, 94.

Lea, A. J. (1964). Ann. rheum. Dis., 23, 480.

McMurray, C., Cayer, D., and Cornatzer, W. E. (1951). Gastroenterology, 17, 294.

Newcombe, D. S., and Cohen, A. S. (1965). Amer J. Med., 38, 156.

Partridge, R. E. H., and Duthie, J. J. R. (1963). Brit. med. J., 1, 611.

Sokoloff, L. (1953). Amer. Heart J., 45, 635.

Stern, J. B., and Sobel, J. H. (1961). Amer. J. Cardiol., 8,670 .

Szatkowski, J., and Inoue, T. (1963). Ibid., 12, 730.

Thomas, A. E., and Morgan, W. K. C. (1956). Ann. rheum. Dis., 15, 176.

Tubbs, O. S., Slade, P. R. H., and Turner-Warwick, M. (1964). Thorax, 19, 555.

Ward, R. (1961). Lancet, 2, 1336.

Wilkinson, M. (1962). Brit. med. J., 2, 1723.
La péricardite associée à l'arthrite rhumatismale

\section{RÉSUMÉ}

On rapporte sur trois cas de péricardite avec épanche- $\overrightarrow{\vec{F}}$ ment associée à l'arthrite rhumatismale et sur un quatri- $\stackrel{\text { ? }}{+}$ ème cas où l'association avec l'arthrite rhumatismale était possible. On décrit les résultats d'autopsie de tous 음 les cas. Deux sur trois malades atteints d'arthrite $\overline{\bar{\rho}}$ rhumatismale franche eurent des signes histologiques de $\vec{\nabla}$ la péricardite rhumatismale et chez le troisième le $\varrho$ microscope révéla la maladie de Hodgkin. On attire § l'attention sur le bas taux de glucose dans l'épanchement péricardiaque d'un cas.

\section{Pericarditis asociada con artritis reumatoide}

\section{SUMARIO}

Se relatan tres casos de pericarditis con derrame asociada con artritis reumatoide y un cuarto caso de $\omega$ asociación con artritis reumatoide probable. Se describen los resultados de necropsia en cada caso. De tres enfermos con artritis reumatoide franca, dos manifes- taron rasgos histológicos de pericarditis reumatoide y en 3 el tercero el microscopio reveló la enfermedad de Hodgkin. Se llama la atención a la baja concentración de glucosa en el derrame pericardíaco de un caso. 